This item was submitted to Loughborough's Research Repository by the author.

Items in Figshare are protected by copyright, with all rights reserved, unless otherwise indicated.

\title{
Volatility spillovers across global asset classes: Evidence from time and frequency domains
}

\section{PLEASE CITE THE PUBLISHED VERSION}

https://doi.org/10.1016/j.qref.2018.05.001

\section{PUBLISHER}

Elsevier ( Board of Trustees of the University of Illinois

\section{VERSION}

AM (Accepted Manuscript)

\section{PUBLISHER STATEMENT}

This paper was accepted for publication in the journal The Quarterly Review of Economics and Finance and the definitive published version is available at https://doi.org/10.1016/j.qref.2018.05.001.

\section{LICENCE}

CC BY-NC-ND 4.0

\section{REPOSITORY RECORD}

Tiwari, Aviral K., Juncal Cunado, Rangan Gupta, and Mark Wohar. 2018. "Volatility Spillovers Across Global Asset Classes: Evidence from Time and Frequency Domains”. Loughborough University.

https://hdl.handle.net/2134/34993. 


\section{Volatility Spillovers across Global Asset Classes: Evidence from Time and Frequency Domains ${ }^{\#}$}

\section{Introduction}

The global financial crisis of 2008-2009, which began with a crisis in the US mortgage market, was rapidly spread across other US financial markets. For example, in the stock market, the Dow Jones lost $6 \%$ of its value during September 2008, and by the end of October, it had lost nearly $20 \%$ and nearly $25 \%$ by the end of 2008 . A similar pattern was observed in the bond market, when the yields on short-term US securities decreased sharply to near zero in November 2008. Furthermore, the Credit Default Swap (CDS) market (a market which was valued at \$60 trillion, twice the size of the US stock market and seven times the value of the mortgage market in 2007) was also hit hard since many financial institutions (big banks and insurance companies) had sold CDS on their subprime securities and were not able to cover the defaults. On the other hand, as far as the exchange rate market is concerned, a sharp appreciation of the US dollar against many currencies was observed during that same period, suggesting that the US dollar currency was a safe "haven” compared to other international currencies (McCauley and McGuire, 2009). All these figures illustrate the high degree of interaction among different financial assets in an economy, and question whether this connectedness among assets may increase the overall risk in the overall financial system, and more specifically, it points to the examination of what is the individual contribution of each of the assets to the overall volatility (or risk). In this context, this paper analyzes the degree of connectedness across four financial markets in the US since the beginning of the financial crisis.

The interaction among returns on various financial assets and their volatilities has been extensively analyzed in the literature. The interdependence among financial markets

\footnotetext{
\# We would like to thank an anonymous referee and Professor Kamil Yilmaz for many helpful comments. However, any remaining errors are solely ours.
} 
is not only important from a regulatory point of view (Kashyap et al., 2008; Brunnermeier et al., 2009; Nier, 2009), but it also has implications for portfolio diversification (Ang and Bekaert, 2002; Aït-Sahalia and Hurd, 2016), hedging strategies (Balcilar et al., 2016), patterns of market integration and market efficiency (Bekaert and Harvey, 2003; Bartram et al., 2007; Forte and Peña, 2009), degree of contagion or spillovers (Bae et al., 2003; Bae and Zhang, 2015; Lehkonen, 2015) or risk management (Scholes, 2000).

From a theoretical point of view, several linkages or channels of cross-market spillovers among financial markets have been documented in the literature (Valseth and Jorgensen, 2011). For example, and as far as the stock and bond market linkages are concerned, the flight-to-quality channel (Li, 2002; Gulko, 2002; Baur and Lucey, 2009; Caballero and Krishnamurthy, 2008) occurs when in periods of high uncertainty, investors sell risky assets (i.e., stocks) and buy the safest and most liquid assets (i.e., bonds). Furthermore, the portfolio-rebalancing hypothesis (Baur, 2010) refers to a change in the composition of a portfolio and involves a purchase of one asset and a sale of another one. According to these two hypotheses, a negative correlation between stock and bond market returns would occur in crisis or periods of high uncertainty. A third channel of information transmission is cross-market-hedging (Fleming et al., 1998; Underwood, 2009), which refers to the purchase or sale of an asset in order to insure a position in another asset, leading to a positive correlation between both assets. Due to these market linkages, volatility is likely to spill over both markets. As far as the relationship between equity and exchange markets, different theoretical approaches have been proposed in the literature to account for the interdependence between these two markets. For example, according to the flow oriented models (Dornbusch and Fisher, 1980), exchange rates will affect stock prices through their effect on the country's trade balance or competitiveness. However, according to the stock oriented models (Frankel, 1983), stock markets will 
impact exchange rates. In both cases, the flow of information between the two markets suggests the existence of volatility linkages between both financial markets. As far as the CDS market is concerned, theoretically and under certain hypotheses, the CDS premium should be roughly equal to the bond spread for the same borrower and maturity. At the same time, variations in the CDS premium (risk default) could easily affect stock markets, which points to the existence of interactive forces among the markets, and thus, allows for volatility transmission among financial markets. In all the previous cases, and considering that agents can focus on different investment horizons when they make investment decisions, the degree of connectedness among different markets will be different at different frequencies (Barunik and Krehlik, 2018). For example, and following these authors, we could assume that a shock affecting expectations about future dividends will more likely affect long-term connectedness than a shock that agents consider to be temporary (and not permanent), which will more likely only affect shortterm connectedness. Thus, a frequency domain analysis of volatility spillovers across countries will allow us to understand the financial connectedness differences at different frequencies.

From an empirical point of view, many papers have analyzed the volatility transmission among different financial markets ${ }^{1}$. For example, Fleming et al. (1998) find strong linkages in volatility in US equity, bond and money markets using data from January 1983 to August 1995 and a spike in the correlation in volatilities coinciding with the 1987 stock market crash. This reflects the time-varying nature of the linkages between volatilities. Diebold and Yilmaz (2012) analyze the existence of volatility spillovers

\footnotetext{
${ }^{1}$ An important research topic in the literature is the analysis of international volatility spillovers (see for example, Dungey and Martin, 2007; Morana and Beltratti, 2008; Diebold and Yilmaz, 2009; Duncan and Kabundi, 2014; Ehrmann et al., 2011; Bayoumi and Bui, 2012; Antonakakis and Vergos, 2013; Apostolakisa and Papadopoulos, 2014; Beirne and Gieck, 2014; Awartania et al., 2013; FernandezRodriguez et al., 2016; Yarovaya et al., 2016; Belke and Dubova, 2018). Despite the relevance of international spillovers, this paper only focuses on the volatility spillovers among US financial markets.
} 
across US equity, bond and exchange markets together with commodity markets using data from 1999 to 2010, again finding that the size of the volatility spillovers is timevarying, with increases observed during periods of financial crisis. Barunik et al. (2016) examine the connectedness of 21 US stocks from seven sectors from 2004 to 2011, finding evidence of asymmetric volatility spillovers across the US stock market. Belke and Gokus (2014) study the volatility patterns of CDS, bond and stock prices for four major US banks during the period 2006-2009 by estimating a multivariate generalized autoregressive conditional heteroscedasticity (GARCH) model. They also find an increase in volatility spillovers in times of crisis.

Although the existence of volatility spillovers, together with the time-varying nature of these spillovers, have already been documented in the literature, which markets are the main transmitters of these spillovers is still an open question ${ }^{2}$. Furthermore, in the context of the regulatory framework of the CDS market after the financial crisis, analyzing the role of the US CDS market as a net transmitter or net receiver of volatility spillovers makes this analysis even more relevant. In this setting, Meng, Gwilym and Varas (2009) studies the volatility transmission among the equity, bond and CDS markets using a multivariate GARCH model. Their aim is to test whether the CDS market is the originator of volatility transmission, and whether volatility in any of the three markets is transmitted to the other two markets. They conclude that none of these three markets is relatively more efficient than the others given its volatility interlinkages. For the European case, Chuliá and Torró (2008) analyze the volatility transmission between stock and bond markets using an asymmetric multivariate GARCH model and find that volatility spillovers are bidirectional. However, Louzis (2015) also examines the Euro

\footnotetext{
2 From an international point of view, the main results suggest that volatility spillovers are mainly transmitted from developed to developing countries (see, for example, Bayoumi and Bui, 2012).
} 
area and finds that the equity market is the main transmitter of spillovers. For the Chinese case, Wang et al. (2016) also finds that the stock market is the net transmitter of spillovers to other countries.

In this context, the objective of this paper is to analyze the connectedness across four global financial markets, namely stock, CDS, foreign exchange, and sovereign bond markets, through the estimation of volatility spillovers among these markets during the period September 2009 to September 2016, using both time and frequency domain frameworks. This study contributes to the existing literature on three fronts. First, the spillover measure proposed by Diebold and Yilmaz (DY, 2009), and based on the VAR model, enables us to quantify the contribution of each financial asset to global market volatility, and to infer which markets are the net transmitters and net receivers of volatility. Second, the Barunik and Krehlik (BK, 2018) frequency domain spillover index enables us to decompose the contribution of each asset to global volatility at different frequencies. Third, the paper also captures the time-varying connectedness among financial assets by calculating both the DY and BK volatility measures using a rollingwindow approach. To the best of our knowledge, this is the first paper to analyze the volatility spillover across these four global financial markets at both time and frequency domains. Most importantly, we achieve this objective by using global indices of volatility connectedness of multiple countries within a specific asset class (as developed by Diebold and Yilmaz, 2014), instead of the various asset returns volatility of multiple countries. This allows us to give a global view of spillovers across asset classes, as we do not need to pick and choose a limited number of countries under each type of assets. ${ }^{3}$

\footnotetext{
${ }^{3}$ Hafner and Herwartz's (2006) methodology is also often used to analyze volatility spillovers across asset classes (Bouri et al., 2017). However, our approach is a multivariate method rather than being bivariate as in Hafner and Herwartz (2006). More importantly, Hafner and Herwartz (2006) computes volatility first using models of conditional variance and then analyzes causality, but in our case, the indices we use are already measuring volatility interconnectedness across the asset classes obtained from multiple economies.
} 
Our main results suggest the following. First, when the DY (2012) methodology is used, the results indicate that the four analyzed global financial markets are not closely linked with each other. In fact, the total connectedness obtained from the four-variable VAR system is $5.08 \%$, indicating a low level of volatility spillovers in the system. Furthermore, the results also suggest that the equity and the CDS markets are net transmitters of volatility, while foreign exchange and bond markets are net receivers of the spillovers. Second, when the BK (2018) spillover index is used, the results suggest that first, at higher frequencies, the degree of connectedness increases, and, second, that the net transmitter of volatility spillovers across the markets is contingent on the frequency under consideration.

The rest of the paper is organized as follows: Section 2 presents the methodology, while Section 3 discusses the data and the results. Finally, Section 4 concludes.

\section{Empirical method}

Let us describe the n-variate process $x_{t}=\left(x_{t, 1}, \ldots, x_{t, n}\right)$ by structural VAR(p) at $t=$ $1, \ldots, T$ as

$$
\Phi(L) x_{t}=\epsilon_{t}
$$

where $\Phi(L)=\sum_{h} \Phi_{h} L^{h}$ is $n \times n$ p-th order lag-polynomial and $\epsilon_{t}$ is white-noise with possibly non-diagonal covariance matrix $\Sigma$. Assuming that the roots of $|\Phi(z)|$ lie outside the unit-circle, the VAR process has following $\mathrm{MA}(\infty)$ representation

$$
x_{t}=\Psi(L) \epsilon_{t},
$$

where $\Psi(L)$ is an $n \times n$ infinite lag polynomial matrix of coefficients. The generalized forecast error variance decomposition (FEVD) can be written as follows: 


$$
\left(\Theta_{H}\right)_{j, k}=\frac{\sigma_{k k}^{-1} \sum_{h=0}^{H-1}\left(\left(\Psi_{h} \Sigma\right)_{j, k}\right)^{2}}{\sum_{h=0}^{H-1}\left(\Psi_{h} \Sigma \Psi_{h}^{\prime}\right)_{j, j}}
$$

where $\Psi_{h}$ is a $n \times n$ matrix of coefficients corresponding to lag $h$, and $\sigma_{k k}=(\Sigma)_{k k}$. The $\left(\Theta_{H}\right)_{j, k}$ denotes the contribution of the $k^{\text {th }}$ variable of the system to the variance of forecast error of the element $j$. Given that the effect do not add up to one within columns by definition in generalized VAR process of FEVDs, to standardize the effects we define

$$
\left(\widetilde{\Theta}_{H}\right)_{j, k}=\left(\Theta_{H}\right)_{j, k} / \sum_{k}\left(\Theta_{H}\right)_{j, k}
$$

The connectedness measure is then defined as the share of variances in the forecasts contributed by other than own errors, or equally as ratio of the sum of the off-diagonal elements to sum of the whole matrix (Diebold and Yilmaz, 2012)

$$
C_{H}=100 \times \frac{\sum_{j \neq k}\left(\tilde{\Theta}_{H}\right)_{j, k}}{\sum\left(\tilde{\Theta}_{H}\right)_{j, k}}=100\left(1-\frac{\operatorname{Tr}\left\{\tilde{\Theta}_{H}\right\}}{\sum\left(\tilde{\Theta}_{H}\right)_{j, k}}\right)
$$

where $\operatorname{Tr}\{\cdot\}$ is the trace operator. Hence, the connectedness is the relative contribution to the forecast variances from the other variables in the system. $C_{H}$ measures the connectedness of the whole system. Further, one can also measure the directional spillovers received by market $i$ from all other markets $k$ and vice-versa and the net spillovers from each market to all other markets is the difference between directional spillover received from the markets to directions spillovers to the market.

Now, we discuss the procedure for measuring connectedness in frequency domain. We know that the generalized FEVDs (GFEVD) are the central part of connectedness, hence we consider a frequency response function $\Psi\left(e^{-i w}\right)=\sum_{h} e^{-i w h} \Psi_{h}$ that can be simply obtained from Fourier transform of the coefficients $\Psi$, with $i=\sqrt{-1}$. The generalized causation spectrum over frequencies $\omega \in(-\pi, \pi)$ is defined as

$$
(\boldsymbol{f}(\omega))_{j, k} \equiv \frac{\sigma_{k k}^{-1}\left|\left(\Psi\left(e^{-i w}\right) \Sigma\right)_{j, k}\right|^{2}}{\left(\Psi\left(e^{-i w}\right) \Sigma \Psi^{\prime\left(e^{+i w}\right)}\right)_{j, j}}
$$


where $\Psi\left(e^{-i w}\right)=\sum_{h} e^{-i w h} \Psi_{h}$ is the Fourier transform of the impulse response $\Psi$. It is important to note that $(\boldsymbol{f}(\omega))_{j, k}$ represents the portion of the spectrum of $\mathrm{j}^{\text {th }}$ variable at frequency $\omega$ due to shocks in $\mathrm{k}^{\text {th }}$ variable. In a sense, we can interpret the quantity as a within frequency causation, as the denominator holds spectrum of the $\mathrm{j}^{\text {th }}$ variable (ondiagonal element of cross-spectral density of $x_{t}$ ) at given frequency $\omega$. To obtain a natural decomposition of original GFEVD to frequencies, we can simply weight the $(\boldsymbol{f}(\omega))_{j, k}$ by the frequency share of variance of the $\mathbf{j}$ variable. The weighting function can be defined as

$$
\boldsymbol{\Gamma}_{\boldsymbol{j}}(\omega)=\frac{\left(\Psi\left(e^{-i w}\right) \Sigma \Psi^{\prime\left(e^{+i w}\right)}\right)_{j, j}}{\frac{1}{2 \pi} \int_{-\pi}^{\pi}\left(\Psi\left(e^{-i \lambda}\right) \Sigma \Psi^{\prime\left(e^{+i \lambda}\right)}\right)_{j, j} d \lambda}
$$

which represents the power of $\mathrm{j}^{\text {th }}$ variable at given frequency, which sums through frequencies to a constant value of $2 \pi$. Note that while the Fourier transform of the impulse response is in general a complex valued quantity, the generalized causation spectrum is the squared modulus of the weighted complex numbers, hence producing a real valued quantity. Formally, let us have a frequency band $d=(a, b): a, b \in(-\pi$, $\pi)$, $a<b$. The generalized FEVD on some frequency band $d$ is defined as

$$
\left(\Theta_{d}\right)_{j, k}=\frac{1}{2 \pi} \int_{d} \boldsymbol{\Gamma}_{j}(\omega)(\boldsymbol{f}(\omega))_{j, k} d \omega
$$

Using the spectra representation of GFEVD, it is straightforward to define connected- ness measures on a given frequency band. Let us define scaled GFEVD on the frequency band $d=(a, b): a, b \in(-\pi, \pi)$, a $<b$ as

$$
\left(\widetilde{\Theta}_{d}\right)_{j, k}=\left(\Theta_{d}\right)_{j, k} / \sum_{k}\left(\Theta_{\mathbf{F}}\right)_{j, k}
$$

The frequency connectedness on the frequency band $d$ is then defined as 


$$
C_{d}^{F}=100\left(\frac{\sum_{j \neq k}\left(\tilde{\Theta}_{d}\right)_{j, k}}{\sum\left(\tilde{\Theta}_{\infty}\right)_{j, k}}-\frac{\operatorname{Tr}\left\{\tilde{\Theta}_{d}\right\}}{\sum\left(\tilde{\Theta}_{\infty}\right)_{j, k}}\right)
$$

The within connectedness on the frequency band $d$ is then defined as

$$
C_{d}^{W}=100\left(1-\frac{\operatorname{Tr}\left\{\widetilde{\Theta}_{d}\right\}}{\sum\left(\tilde{\Theta}_{d}\right)_{j, k}}\right) \text {. }
$$

It is worthy to note that the within connectedness gives us the connectedness effect that happens within the frequency band and is weighted by the power of the series on the given frequency band exclusively. On the other hand, the frequency connectedness decomposes the original connectedness into distinct parts that in sum give the original connectedness measure.

\section{Data and preliminary analysis}

We use daily data covering the period from $1^{\text {st }}$ September, 2009 to $30^{\text {th }}$ September, 2016. The variables considered are the overall indices of global connectedness of stock, CDS, foreign exchange and sovereign bond markets developed by Diebold and Yilmaz (2014). These global level interconnectedness indices within a specific asset class are computed using the daily asset market return volatilities of multiple countries. These indices are available for download from: http://financialconnectedness.org/data.html.

Specifically, Diebold-Yilmaz Connectedness Index (DYCI) methodology is applied to daily stock market index return volatilities from 45 countries, US Dollar exchange rate return volatilities of 28 currencies, daily 10-year government bond return volatilites in 12 major economies, and daily credit default swap returns for 5-year government bonds in 26 countries. The results are based on generalized variance decompositions (with 10-day forecast horizon) obtained from a VAR(3) model of daily range volatilities. The VAR model is estimated using the elastic net shrinking and 
selection procedure, which combines Lasso and Ridge estimators. Dynamic connectedness measures are obtained from the estimation of the VAR model over 200day rolling windows. ${ }^{4}$ An important issue (possibly, a word of caution), as pointed out by an anonymous referee, that needs highlighting is that while the model used is the same across the various asset classes, the number of countries used to obtain the global volatility spillover indices are different. However, it must be realized, that even though the countries are different, the ones that were chosen for each asset class, besides having consistent data over long-enough periods, are the major players in each asset category in terms of volume traded. ${ }^{5}$ So, while, we cannot say for sure how much the different number of countries in each asset class is driving our results, as we do not have access to the underlying volatility series to compute the overall connectedness index using the same countries across the four assets, we believe that our conclusions would continue to hold qualitatively, given the importance of the countries chosen within a specific asset-type.

We have transformed the data by first-differencing the natural logs of data for all analyses, giving us a total of 1814 observations, effectively starting from $2^{\text {nd }}$ September, 2009. The key motivation of this study is to show how much the relationship among the considered indices at global level can be understood in a systemic way. A time series plot of the used series is presented in Figure 1.

(Insert Figure 1 around here)

\footnotetext{
${ }^{4}$ Note that, the total connectedness for stocks and bonds are originally based on 150-day rolling windows. However, Professor Kamil Yilmaz, upon our request, since we do not have the raw data for the four asset classes of each country, kindly provided us the indices based on 200-day rolling windows. We are deeply indebted to him for this, and would also like to thank an anonymous referee for pointing out to us that comparisons are likely to be unfair across the asset classes, as the size of the window differs in generating the underlying indices.

${ }^{5}$ We would again like to thank Professor Kamil Yilmaz for pointing this to us.
} 
Descriptive statistics of these return series are reported in Table 1. To ensure that all the VAR components are stationary, the augmented Dickey Fuller (ADF)-Generalized Least Squares (GLS) unit root test and Kwiatkowski-Phillips-Schmidt-Shin (KPSS) stationary test are used, and the results show clearly that all the log-differenced series satisfy this condition.

(Insert Table 1 around here)

Among all return series, the global stock market index return (Stock market, hereafter) has the highest mean followed by the foreign exchange market index return (Forex market, hereafter), whereas the CDS return has the lowest mean with the sovereign bond market index return (Bond market, hereafter) ranking above it. Among all series, Bond market return has experienced the highest volatility followed by the Forex market. Note that the CDS market index return and Bond market index return have negative skewness, whereas the Stock market return and CDS market return have very high levels of excess kurtosis.

\section{Empirical results and discussion}

Following the methodology described in Section 2, a four variable VAR is first estimated with the Akaike Information Criterion (AIC) criteria used to automatically choose lag length. A 100-period ahead forecasting horizon $(\mathrm{H})$ for variance decomposition is used

to construct the connectedness table (see Table 2). The choice of forecasting horizon is based on BK (2018) because this approach does not work if $\mathrm{H}<100$. The total connectedness in this four-variable VAR system is 5.08\%, which indicates that these markets are not closely linked with each other as we observed from the correlation matrix. This number represents how much spillover effects exist within this system. Results of 
DY (2012) and BK (2018) spillovers are presented in Table 2. The low level of the total connectedness index obtained with DY (2012) suggests a low level of connection among the four markets, and thus, the existence of diversification opportunities for investors. Furthermore, from the results of DY (2012) spillover analysis, we find that the Stock market contributes most in the system, while Bond and Forex markets contribute about $0.81 \%$ and $1.47 \%$ respectively, with the lowest contribution in the system made by the CDS market. This result suggests that from a regulatory point of view, regulatory initiatives should be taken in the stock market, since it contributed most to the total volatility in the system during the analyzed period, which is not surprising, given that we are basically analyzing the period post the global financial crisis. Further, when we decompose the spillover, based on frequencies, following the approach of BK (2018), we find that total spillover from the lowest frequency (freq1, which corresponds to 1 to 4 days) contribute most to the total connectedness, i.e., 3.12\%. Contribution from the frequency corresponding to 4 to 10 days, freq 2, is just $1.15 \%$, and whereas contribution from more frequencies more than 10 days (freq3) corresponds to $0.81 \%$ of the total connectedness. Furthermore, across-frequencies, the contribution of the stock market is largest, which is followed by the Forex market as also observed under the purely timedomain approach of DY (2012).. The contribution of Bond market at freq1 is fairly high compared to contributions at freq2 and freq3, as is the case of the CDS. In freq1 and freq2, contribution from the CDS market is lowest, with Bond market taking that spot in freq3. According to these results, we could conclude that the total connectedness index among the four markets is higher in the short-run rather than in the long-run, suggesting that portfolio diversification opportunities are thus lower in in the very short-run.

(Insert Table 2 around here) 
We can now construct “net directional connectedness” with the help of Table 2. Results of "net directional connectedness" are reported in Table 3. It is evident from the DY (2012) results as reported in Table 3, that the Stock and CDS markets have net negative spillover, whereas the Forex and Bond markets have net positive spillover in the system. Further, the Stock market has the highest net negative and the Bond market has the highest net positive spillover in the system. Next, when we consider the results obtained from the BK (2018) method, we find that at frequency 1, the CDS and Forex markets have net negative spillover, whereas the other two assets have net positive spillover in the system. Findings at freq2 and freq3, are the same, with Stock and Bond markets having net negative spillovers, with positive values of the same witnessed by CDS and Forex markets. In other words, at relatively longer horizons, the sign of net spillovers between the assets changes sign. So, we can say that the DY results are driven by longer-horizon net spillovers of Stock and Forex markets, while the Freq1 drives the DY (2012) net spillovers results for CDS and Bonds markets. These findings are clearly important and one could have not obtained the horizon-based results with the simple DY (2012) method, and it thus highlights the importance of different frequencies that are considered for the analysis. For example, and based on these results, and from a regulatory point of view, regulatory policies aimed to reduce global risk should be directed to the Stock and Bond markets according to the results obtained using frequency 1, and to the CDS and Forex markets when longer periods (frequencies 2 and 3) are considered. If we had just followed the time-domain approach, policy makers would have aimed to design policies to reduce volatility from Bonds and Forex markets always irrespective of the length of the investment horizons, leading to clearly incorrect policy moves, as policy decisions are clearly frequency-dependent.

(Insert Table 3 around here) 
To further investigate the results in more detail, we construct the "pairwise net directional connectedness”, and report results in Table 4. From the DY (2012) results reported in Table 4, it is evident that net connectedness between the Stock to Forex and Bond markets is positive whereas between the Stock and CDS market is negative. Further, results show that net connectedness between CDS-Bond and Forex-Bond markets are positive, while that between CDS-Forex is negative. However, when we investigate the connectedness at different frequencies, we find that barring the cases of CDS with Forex and Bonds markets, where the sign of net connectedness is the same at all frequencies and the same as the DY approach. However, this is not true of for the other pairs, with the signs tending to vary depending on frequencies, and the sign on the DY (2012) approach emanating from the overall strength at freq1, freq2 and freq 3. For instance the negative (positive) sign on the net spillovers between Stock-CDS (Forex-Bonds) in the DY (2012) approach comes from freq1, while the positive sign for Stocks-Forex and Stocks-Bonds pair comes from freq2 and freq3, and freq1 and freq2 respectively. Finally, the negative sign between Forex-Bonds is purely. These results highlight again the importance of considering different frequencies in the analysis.

(Insert Table 4 around here)

\subsection{Rolling-windows analysis}

Last but not least, we used rolling window approach to capture the time varying overall connectedness and pairwise net directional connectedness relationship between the four variables of our system. For the rolling window by keeping the forecast horizon 100 we used a window size of 300 days (about one-fifth of total observations) to allow 
for a large enough sample size in each VAR estimation, and to be able to reflect the timevarying characteristics. The results of overall connectedness obtained through DY method and BK methods are presented in Figure 2. The data points plotted in the graph refer to the total connectedness (in time and frequency domain) of each window and its position corresponds to the end of each window. For example, the first window starts from December 22, 2010 and ends in April 19, 2012 (300 total observations). The total connectedness calculated for this window is about $6 \%$, and this number's position is in April 19, 2012 (the first date in the figure). Results from the DY spillovers show that overall connectedness of the system during 2011 to 2013 is roughly stable which fluctuates around 6\% to 7\%, with it being over $10 \%$ for the early half of 2011 , but going below 5\% between mid-2012 to mid-2013. The peak is observed at the end of the sample, with the overall spillover being higher than 25\%. Figure 2 also plots the rolling-windows version of total connectedness the frequency domain analysis, which highlights that the DY (2012) results are primarily driven by freq1, i.e., the short-run. Note that, the rollingwindow results are reported in a way similar for all the graphs. These results are in line with previous papers that document a time-varying volatility spillover effects (Fleming et al., 1998; Belke and Gokus, 2014).

(Insert Figure 2 around here)

Let us consider the rolling-windows version of pairwise net directional connectedness in time and frequency domain versions. Results are reported in Figure 3. It is evident from Figure 3 that pairwise net directional connectedness between the assets is highly volatile, though mostly positive, but characterized by large negative swings, especially for the currency-bond markets towards the end of the sample. Now if we consider the frequency domain versions of the pairwise net directional connectedness, we find that results of net directional connectedness between the asset classes at frequency 
between 1 to 4 days (i.e., freq1) are similar to the results of overall connectedness. The net directional connectedness between the Stock and CDS markets, and Stock and Bond markets are negative after 2015 whereas it is positive between Stock and Forex markets, and CDS and Forex markets, with negative values observed at early part of the sample, with a similar pattern also obtained for CDS and Bond markets.

(Insert Figure 3 around here)

\section{Conclusions}

This paper builds upon the existing literature on volatility spillovers across financial markets and examines the degree of connectedness across four financial markets in the US (global stock market, CDS market, Forex market and sovereign bond market) using data from September 2009 to September 2016, using both a time-domain and a frequency domain framework. The main results are the following. When Diebold and Yilmaz (2012) methodology is applied, the estimated total connectedness index is 5.08\%, suggesting a low level of connection among the four markets, and implying that there were diversification options during the financial crisis. Furthermore, the stock market contributed most to the total volatility in the system during the analyzed period, a result, though not of immense surprise, justifies the regulatory initiatives taken in this market. Moreover, the results also suggest that the stock and CDS markets are net transmitters of volatility, while foreign exchange and sovereign bond markets are net receivers of the spillovers. From a theoretical point of view, and considering that agents can focus on different investment horizons when they make investment decisions, the degree of connectedness among different markets will be different at different frequencies, so the same analysis is repeated using the Barunik and Krehlik (2018) frequency-domain analysis. When this analysis is carried out, the results suggest, first, that at higher frequencies, the degree of connectedness is higher relative to lower ones, and, second, 
that the net transmitter of volatility is dependent on the frequency we are analyzing. We observe that stock and bond markets become the net transmitter of volatility spillovers across the markets at the higest frequency, while at lower frequencies, both the Forex and the CDS markets are net transmitters of volatility. These results suggest that diversification opportunities are different at different frequencies, and, in this case, diversification opportunities among financial assets seem to be lower at higher frequencies. At the same time, the role of the global stock market as net transmitter of volatility spillover decreases (in favor of the currency market) at higher frequencies. Therefore, and based on this result, regulatory policies aimed to reduce long-term risk should be more oriented to the foreign exchange market than to the stock market, which contributes most to the volatility in the system at higher frequencies. 


\section{References}

Aït-Sahalia; Y., Hurd, T., 2016. Portfolio choice in markets with contagion. Journal of Financial Econometrics 14, 1-28.

Ang, A., Bekaert, G., 2002. International asset allocation with regime shifts. Review of Financial Studies 15, 1137-1187.

Antonakakis, N., Vergos, K., 2013. Sovereign bond yield spillovers in the Euro zone during the financial and debt crisis. Journal of International Financial Markets, Institutions and Money 26, 258-272.

Apostolakisa, G., Papadopoulos, A.P., 2014. Financial stress spillovers in advanced economies. Journal of International Financial Markets, Institutions and Money 32, 128-149.

Awartania, B., Maghyerehb, A.I., Al Shiabc, M., 2013. Directional spillovers from the US and the Saudi market to equities in the Gulf Cooperation Council countries. Journal of International Financial Markets, Institutions and Money 27, 224-242.

Bae, K.H., Karolyi, A., Stulz, R., 2003. A new approach to measuring financial contagion. Review of Financial Studies 16, 717-763.

Bae, K.H., Zhang, X., 2015. The cost of stock market integration in emerging markets. Asia Pacific Journal of Financial Studies 44, 1-23.

Balcilar, M., Demirer, R., Hammoudeh, S., Nguyen, D.K., 2016. Risk spillovers across the energy and carbon markets and hedging strategies for carbon risk. Energy Economics 54, 159-172.

Bartram, S.M., Taylor, S.J., Wang, Y.H., 2007. The euro and European financial market dependence. Journal of Banking and Finance 31, 1461-1481. 
Barunik, J., Krehlik, T., 2018. Measuring the frequency dynamics of financial connectedness and systemic risk. Journal of Financial Econometrics, https://doi.org/10.1093/jjfinec/nby001.

Barunik, J., Koenda, E., Vácha, L., 2016. Asymmetric connectedness of stocks: bad and good volatility spillovers. Journal of Financial Markets 27, 55-78.

Baur, D.G., 2010. Stock-bond co-movements and cross-country linkages. International Journal of Banking, Accounting and Finance 2, 111-129.

Baur, D.G., Lucey, B.M., 2009. Flight and contagion. An empirical analysis of stockbond correlations. Journal of Financial Stability 5, 339-352.

Bayoumi, G., Bui, T., 2012. Global bonding: Do US bond and equity spillovers dominate global financial markets? IMF Working Paper 12/298, International Monetary Fund, Washington.

Beirne, J., Gieck, J., 2014. Interdependence and contagion in global asset markets. Review of International Economics 22, 639-659.

Bekaert, G., Harvey, C.R., 2003. Emerging markets finance. Journal of Empirical Finance 10, 3-55.

Belke, A., Gokus, C., 2014. Volatility Patterns of CDS, Bond and Stock Markets before and during the Financial Crisis: Evidence from Major Financial Institutions. International Journal of Economics and Finance 6, 53-70.

Belke, A., Dubova, I., 2018. International spillovers in global asset markets. Economic Systems 42, 3-17. 
Bouri, E., de Boyrie, M.E., Pavlova, I. 2017. Volatility transmission from commodity markets to sovereign CDS spreads in emerging and frontier countries. International Review of Financial Analysis, 49, 155-165.

Brunnermeier, M.K., Crocket, A., Persaud, A.D., Shin, H., 2009. The fundamental principles of financial regulation. Geneva London: International Center for Monetary and Banking Studies Centre for Economic Policy Research.

Caballero, R.J., Krishnamurthy, A., 2008. Collective risk management in a flight to quality episode. Journal of Finance 63, 2195-2230.

Chuliá, H., Torró, H., 2008. The economic value of volatility transmission between the stock and bond markets. The Journal of Future Markets 28, 1066-1094.

Diebold, F.X., Yilmaz, K., 2009. Measuring financial asset return and volatility spillovers, with application to global equity markets. The Economic Journal 119, 158171.

Diebold, F.X., Yilmaz, K., 2012. Better to give than receive: predictive directional measurement of volatility spillovers. International Journal of Forecasting 28, 57-66.

Diebold, F.X., Yilmaz, K., 2014. Financial and Macroeconomic Connectedness: A Network Approach to Measurement and Monitoring. First Edition, Oxford University Press, Oxford, UK.

Dornbusch, R., Fischer, S., 1980. Exhcange rates and the current account. American Economic Review 70, 960-971. 
Duncan, A.S., Kabundi, A., 2014. Gobal financial crises and time-varying volatility comovement in world equity markets. South African Journal of Economics 82, 531550.

Dungey, M., Martin, V.L., 2007. Unravelling financial market linkages during crises. Journal of Applied Econometrics 22, 89-199.

Ehrmann, M., Fratzscher, M., Rigobon, R., 2010. Stocks, bonds, money markets and exchange rates: measuring international financial transmission. Journal of Applied Econometrics 26, 948-974.

Fernandez-Rodriguez, F., Gomez-Puig, M., Sosvilla-Rivero, S., 2016. Using connectedness analysis to assess financial stress transmission in EMU sovereign bond market volatility. Journal of International Financial Markets, Institutions and Money 43, 126-145.

Fleming, J., Kirby, C., Ostdiek, B., 1998. Information and volatility linkages in the stock, bond, and money markets. Journal of Financial Economics 49, 111-137.

Forte, S., Peña, J.I., 2009. Credit spreads : An empirical analysis on the informational content of stocks, bonds, and CDS. Journal of Banking and Finance 33, 2013-2025.

Frankel, J.A., 1983. Monetary and portfolio-balance models of exchange rate determination. In Economic Interdependence and Flexible Exchange Rates, edited by Bhandari, J.S. and Putnampp, B.H., Cambridge: MIT, 84-115.

Hafner, C. M., Herwartz, H. 2006. A Lagrange multiplier test for causality in variance. Economics Letters, 93(1), 137-141. 
Kashyap, A.K., Raghuram, G.R., Stein, J.C., 2008. Rethinking capital regulation. Economic Symposium “Maintaining stability in a changing financial system”. Federal Reserve Bank of Kansas City.

Lehkonen, H., 2015. Stock market integration and the global financial crisis. Review of Finance 19, 2039-2094.

Li, L., 2002. Macroeconomic factors and the correlation of stock and bond returns. Yale ICF Working Paper 02-46.

Louzis, D. 2015. Measuring spillover effects in Euro area financial markets: a disaggregate approach. Empirical Economics 49, 1367-1400. I

McCauley, R., McGuire, P., 2009. Dollar appreciation in 2008: safe haven, carry trades, dollar shortage and overhedging. BIS Quarterly Review, 85-93.

Meng, L., Gwilym, O., Varas, J., 2009. Volatility transmission among the CDS, equity and bond markets. Journal of Fixed Income 18, 33-46.

Morana, C., Beltratti, A., 2008. Comovements in international stock markets. Journal of International Financial Markets, Institutions and Money 18, 31-45.

Nier, E., 2009. Financial stability frameworks and the role of Central Banks: Lessons from the crisis. IMF Working Paper 09/70.

Scholes, M.S., 2000. Crisis and Risk Management. American Economic Review 90, 1721.

Underwood, S., 2009. The cross-market information content of stock and bond order flow. Journal of Financial Markets 12, 268-289. 
Valseth, S., Jorgensen, K. 2011. A direct approach to cross market spillovers. SSRN Working Papers 1984775.

Wang, G.J., Xie, C., Jiang, Z.Q., Stanley, H.E. 2016. Who are the net senders and recipients of volatility spillovers in China's financial markets? Finance Research Letters 18, 255-262.

Yarovaya, L., Brzeszczynski, J., Lau, C.K., 2016. Intra and inter-regional return and volatility spillovers across emerging and developed markets: Evidence from stock indices and stock index futures. International Review of Financial Analysis 43, 96114. 
Figure-1: Time series plot log-level and log-returns data

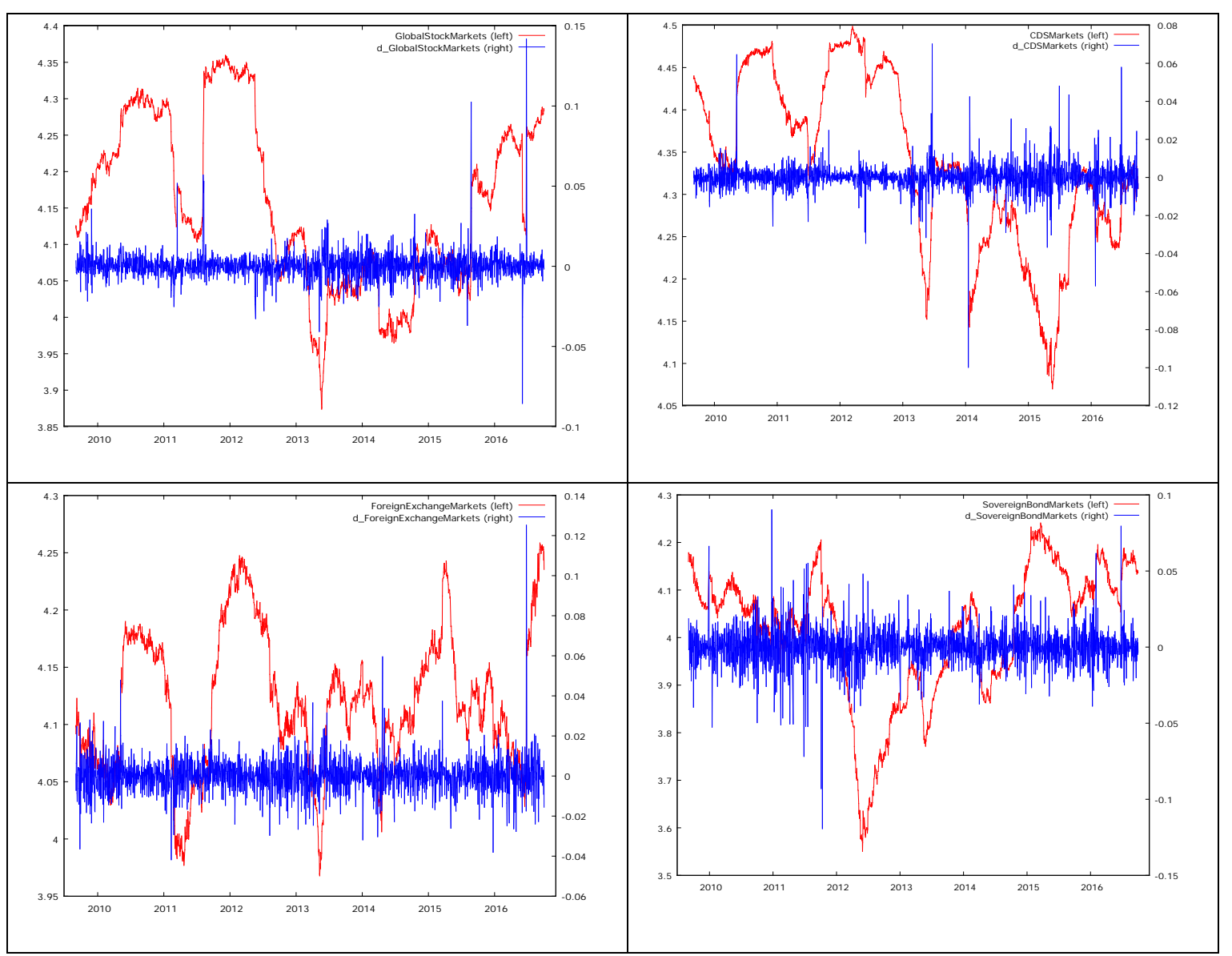


Figure 2: DY (2012) total spillover and BK (2018) across-frequencies spillovers

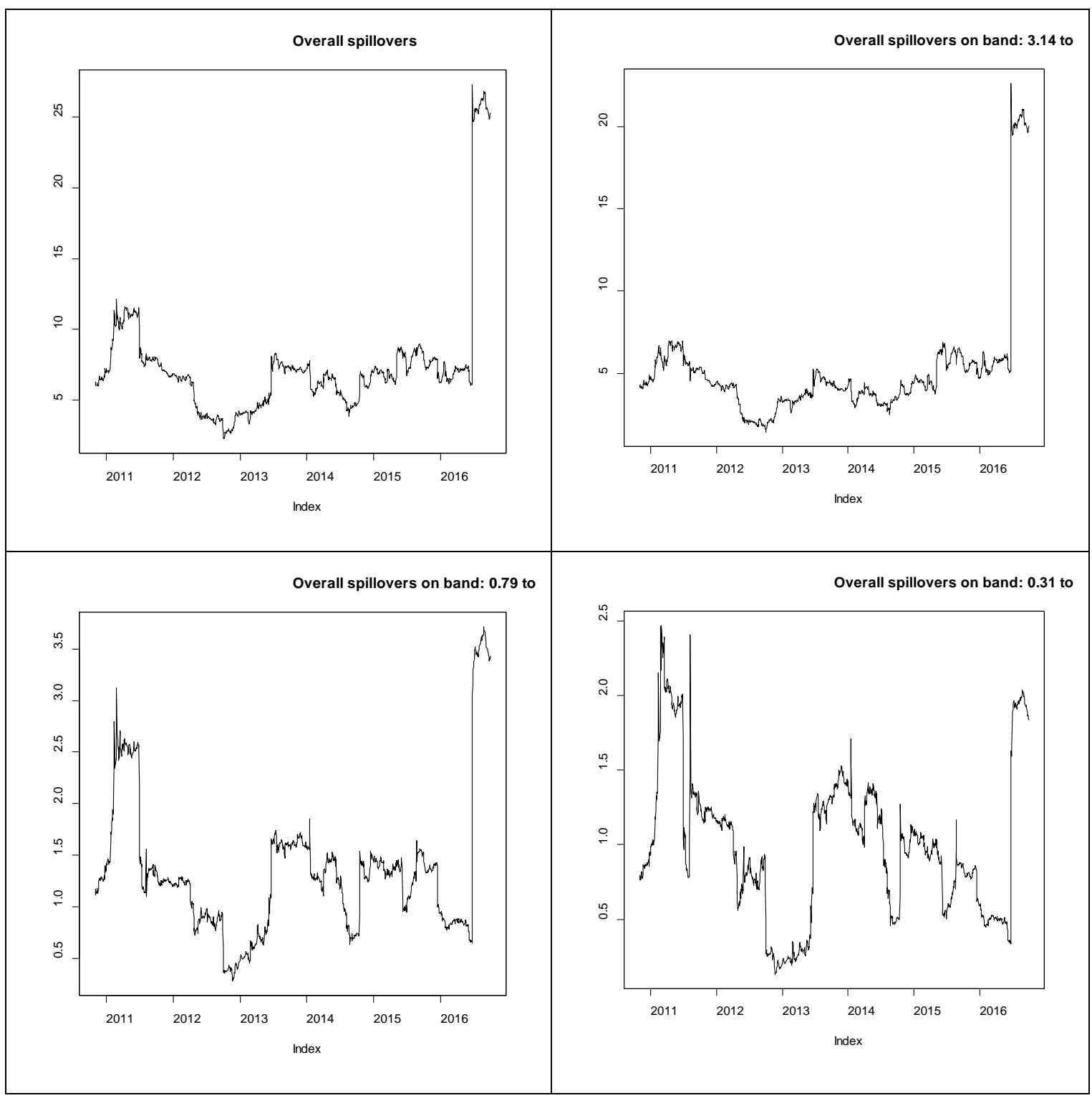

Figure 3: DY (2012) pairwise net directional connectedness and BK (2018) pairwise net directional connectedness across-frequencies 


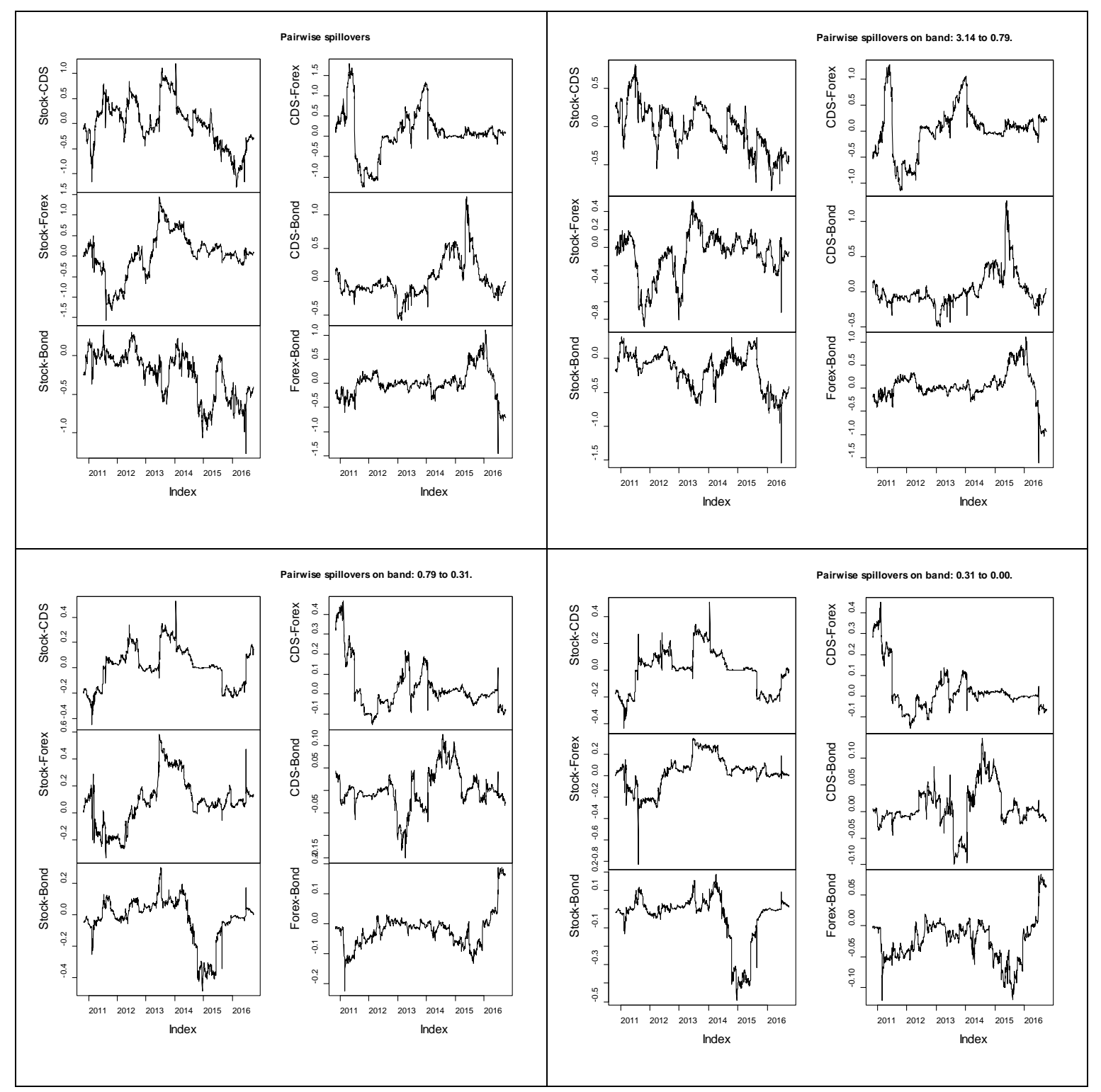


Table 1: Descriptive Statistics

\begin{tabular}{|c|c|c|c|c|}
\hline & $\begin{array}{l}\text { Global Stock } \\
\text { Markets }\end{array}$ & CDS Markets & $\begin{array}{l}\text { Foreign Exchange } \\
\text { Markets }\end{array}$ & $\begin{array}{l}\text { Sovereign Bond } \\
\text { Markets }\end{array}$ \\
\hline Mean & 8.9E-05 & $-7.2 \mathrm{E}-05$ & 7.6E-05 & $-1.3 \mathrm{E}-05$ \\
\hline Median & $-1.3 \mathrm{E}-05$ & $-8.6 \mathrm{E}-05$ & 0.0002 & 0.0001 \\
\hline Minimum & -0.0859 & -0.1001 & -0.0418 & -0.1193 \\
\hline Maximum & 0.1413 & 0.0699 & 0.1251 & 0.0902 \\
\hline Std. Dev. & 0.0088 & 0.0074 & 0.0088 & 0.0129 \\
\hline C.V. & 99.042 & 102.85 & 116.45 & 977.53 \\
\hline Skewness & 2.962 & -0.3501 & 1.6275 & -0.3924 \\
\hline Ex. kurtosis & 54.253 & 32.325 & 24.592 & 9.8997 \\
\hline $5 \%$ perc. & -0.0116 & -0.0010 & -0.0139 & -0.0192 \\
\hline 95\% perc. & 0.0106 & 0.0092 & 0.0132 & 0.0186 \\
\hline IQ range & 0.0074 & 0.0057 & 0.0088 & 0.0128 \\
\hline \multicolumn{5}{|l|}{ Normality tests } \\
\hline $\begin{array}{l}\text { Doornik-Hansen } \\
\text { test }\end{array}$ & $4142.34 * * *$ & $6858.96^{* * *}$ & $2861.37 * * *$ & $1714.29 * * *$ \\
\hline Shapiro-Wilk W & $0.7771^{* * *}$ & $0.7927 * * *$ & $0.9024 * * *$ & $0.9128 * * *$ \\
\hline Lilliefors test & $0.1032 * * *$ & $0.1165 * * *$ & $0.0647 * * *$ & $0.0707 * * *$ \\
\hline Jarque-Bera test & $225122 * * *$ & $79016.6^{* * *}$ & $46511.8 * * *$ & $7454.06 * * *$ \\
\hline \multicolumn{5}{|l|}{ Unit root tests } \\
\hline ADF-GLS test & $-9.7664 * * *$ & $-51.8800 * * *$ & $-51.2177 * * *$ & $-4.3175 * * *$ \\
\hline KPSS test & 0.1205 & 0.0752 & 0.0675 & 0.2047 \\
\hline
\end{tabular}

Note: *** denotes significant at $1 \%$ level of significance. 
Table 2: DY (2012) and BK (2018) spillover results

\begin{tabular}{|c|c|c|c|c|c|c|}
\hline \multicolumn{7}{|c|}{ DY Spillover Table } \\
\hline & Stock & CDS & Forex & Bond & FROM & \\
\hline Stock & 91.76 & 1.75 & 4.39 & 2.1 & 2.06 & \\
\hline CDS & 2.03 & 97 & 0.7 & 0.26 & 0.75 & \\
\hline Forex & 3.87 & 0.86 & 94.14 & 1.14 & 1.47 & \\
\hline Bond & 2.09 & 0.16 & 0.98 & 96.77 & 0.81 & \\
\hline TO & 2 & 0.69 & 1.52 & 0.88 & 5.08 & \\
\hline \multicolumn{7}{|c|}{ BK Spillover results } \\
\hline \multicolumn{7}{|c|}{$\begin{array}{l}\text { Freq1: The spillover table for band: } 3.14 \text { to } 0.79 \text { Roughly corresponds to } 1 \text { days } \\
\text { to } 4 \text { days. }\end{array}$} \\
\hline & Stock & CDS & Forex & Bond & FROM_ABS & FROM_WTH \\
\hline Stock & 66.18 & 0.85 & 2.26 & 1.27 & 1.1 & 1.37 \\
\hline CDS. & 1.27 & 79.26 & 0.44 & 0.22 & 0.48 & 0.6 \\
\hline Forex & 2.58 & 0.49 & 79.56 & 1.01 & 1.02 & 1.27 \\
\hline Bond & 1.26 & 0.15 & 0.7 & 83.33 & 0.53 & 0.66 \\
\hline TO_ABS & 1.28 & 0.37 & 0.85 & 0.63 & 3.12 & \\
\hline TO_WTH & 1.59 & 0.46 & 1.06 & 0.78 & & 3.89 \\
\hline \multicolumn{7}{|c|}{$\begin{array}{l}\text { Freq 2: The spillover table for band: } 0.79 \text { to } 0.31 \text { Roughly corresponds to } 4 \text { days } \\
\text { to } 10 \text { days. }\end{array}$} \\
\hline & Stock & CDS & Forex & Bond & FROM_ABS & FROM_WTH \\
\hline Stock & 15.71 & 0.52 & 1.26 & 0.52 & 0.57 & 4.56 \\
\hline CDS & 0.41 & 11.39 & 0.15 & 0.02 & 0.14 & 1.15 \\
\hline Forex & 0.73 & 0.21 & 9.65 & 0.1 & 0.26 & 2.06 \\
\hline Bond & 0.5 & 0.01 & 0.17 & 9.09 & 0.17 & 1.34 \\
\hline TO_ABS & 0.41 & 0.18 & 0.4 & 0.16 & 1.15 & \\
\hline TO_WTH & 3.25 & 1.45 & 3.14 & 1.26 & & 9.1 \\
\hline
\end{tabular}


Freq3: The spillover table for band: 0.31 to 0.00 Roughly corresponds to more than 10 days

\begin{tabular}{|l|c|c|c|c|c|c|}
\hline & Stock & CDS & Forex & Bond & FROM_ABS & FROM_WTH \\
\hline Stock & 9.87 & 0.38 & 0.87 & 0.31 & 0.39 & 5.42 \\
\hline CDS. & 0.35 & 6.35 & 0.11 & 0.02 & 0.12 & 1.68 \\
\hline Forex & 0.55 & 0.16 & 4.93 & 0.03 & 0.19 & 2.62 \\
\hline Bond & 0.33 & 0 & 0.11 & 4.35 & 0.11 & 1.56 \\
\hline TO_ABS & 0.31 & 0.14 & 0.27 & 0.09 & $\mathbf{0 . 8 1}$ & \\
\hline TO_WTH & 4.32 & 1.89 & 3.8 & 1.27 & & 11.28 \\
\hline
\end{tabular}


Table 3: Net Spillovers

\begin{tabular}{|l|c|c|c|c|}
\hline $\begin{array}{l}\text { Total DY } \\
(2012)\end{array}$ & Stock & CDS & Forex & Bond \\
\hline & -0.0618 & -0.0585 & 0.0520 & 0.0684 \\
\hline BK (2018) & & & & \\
\hline Freq1 & Stock & CDS & Forex & Bond \\
\hline & 0.1828 & -0.1121 & -0.1691 & 0.0985 \\
\hline Freq2 & Stock & CDS & Forex & Bond \\
\hline & -0.1652 & 0.0387 & 0.1358 & -0.0094 \\
\hline Freq3 & Stock & CDS & Forex & Bond \\
\hline & -0.0794 & 0.0148 & 0.0853 & -0.0207 \\
\hline
\end{tabular}

Table 4: Net-pairwise Spillover

\begin{tabular}{|l|c|c|c|c|c|c|}
\hline $\begin{array}{l}\text { Total DY } \\
(2012)\end{array}$ & Stock-CDS & Stock-Forex & Stock-Bond & CDS-Forex & CDS-Bond & Forex-Bond \\
\hline & -0.0723 & 0.1318 & 0.0023 & -0.0395 & 0.0258 & 0.0403 \\
\hline BK (2018) & & & & & & \\
\hline Freq1 & Stock-CDS & Stock-Forex & Stock-Bond & CDS-Forex & CDS-Bond & Forex-Bond \\
\hline & -0.1061 & -0.0788 & 0.0021 & -0.0129 & 0.0189 & 0.0775 \\
\hline Freq2 & Stock-CDS & Stock-Forex & Stock-Bond & CDS-Forex & CDS-Bond & Forex-Bond \\
\hline & 0.0281 & 0.1317 & 0.0054 & -0.0140 & 0.0034 & -0.0181 \\
\hline Freq3 & Stock-CDS & Stock-Forex & Stock-Bond & CDS-Forex & CDS-Bond & Forex-Bond \\
\hline & 0.0057 & 0.0789 & -0.0052 & -0.0127 & 0.0036 & -0.0191 \\
\hline
\end{tabular}

